\title{
Bedload transport monitoring with acoustic sensors in the Swiss Albula mountain river
}

\author{
Dieter Rickenmann, Gilles Antoniazza, Carlos R. Wyss, Bruno Fritschi, and Stefan Boss \\ Swiss Federal Research Institute WSL, Birmensdorf, 8903, Switzerland \\ Correspondence to: D. Rickenmann (dieter.rickenmann@wsl.ch)
}

Published: 3 March 2017

\begin{abstract}
Bedload transport measurements with acoustic sensors were obtained during summer 2015 in the Albula River in Switzerland. An impact plate measuring system was used with geophone and accelerometer sensors. This system provides indirect estimations of bedload transport in water courses. In April 2015, 30 impact sensors were installed in a new permanent measuring station to monitor continuously bedload transport in a mountain river with a large annual rate of sediment transport (around $90000 \mathrm{~m}^{3} \mathrm{yr}^{-1}$ ). Records of the first year of measurement showed that (i) the signal response in terms of geophone and accelerometer impulses is comparable for both types of sensors; (ii) there is a good correlation between discharge data and impulses recorded by both types of sensors; (iii) the critical discharge at the start of bedload transport is around $5 \mathrm{~m}^{3} \mathrm{~s}^{-1}$; (iv) a mean calibration factor for the geophone impulses can be estimated which is in a similar range as values determined from other sites with field calibration measurements.
\end{abstract}

\section{Introduction}

Impact measuring systems have been used successfully over the last decade to estimate bedload transport in mountain streams (Rickenmann, 2017a, b; Rickenmann et al., 2012, 2014; Reid et al., 2007; Raven et al., 2010; Beylich and Laute, 2014; Wyss et al., 2016a, b, c). As pointed out in the conclusions of the International Bedload Surrogate Monitoring Workshop in April 2007 (Gray et al., 2010) and of the International Workshop of Acoustic and Seismic Monitoring of Bedload and Mass Movements in September 2013 (Rickenmann et al., 2013), indirect impact measuring systems have the advantage of providing continuous measurements of bedload transport dynamics in both time and over a cross section whilst minimizing spatial and temporal modification of hydraulic conditions near the sensors. Nevertheless, further laboratory and field calibration experiments are needed to obtain reliable measurements of bedload transport (i.e. Rickenmann et al., 2012; Wyss et al., 2016b, c). The principle of these indirect measuring systems is to record the signals generated by the vibration induced by moving bedload particles impacting on a structure, like pipes, plates or columns (Rickenmann, 2017a, b). Impact measuring systems include the Swiss plate geophone (Rickenmann et al., 2012,
2014; Wyss et al., 2016a, b, c), the Japanese pipe hydrophone (Mizuayama et al., 2010a, b), and a wide range of other measuring devices using impact structures and different types of sensors such as geophones, accelerometers, and piezoelectric sensors (Krein et al., 2008; Reid et al., 2007; Raven et al., 2010; Tsakiris et al., 2014; Beylich and Laute, 2014).

Many previous studies using impact sensors have been conducted in small headwater catchments with high channel slopes, but relatively low annual rates of transport (i.e. Rickenmann et al., 2012, 2014; Reid et al., 2007; Raven et al., 2010). Thus, experience with impact measuring systems and bedload transport in larger alpine catchments with high annual rates of transport and bedload potential is rare, though bedload transport processes in these rivers are associated with important scientific, social and economic challenges (i.e. Badoux et al., 2014).

The Swiss plate geophone system has previously been applied successfully in many alpine streams (Rickenmann et al., 2014). Since April 2015, a new surrogate bedload transport measuring system has been operational in the Albula River in Tiefencastel, canton Grisons, Switzerland. The measurements are performed with the Swiss plate geophone system, also using accelerometer sensors in addition to the geophone sensors. The objective of this paper is to report the 
bedload transport monitoring during the first summer of measurements, and to compare measurements using both geophone and accelerometer sensors. The study site is of particular interest because of the relatively high annual sediment transport rate of about $90000 \mathrm{~m}^{3} \mathrm{yr}^{-1}$.

\section{Study site and measuring system}

At the Albula River in Switzerland, the "Solis" hydropower reservoir was built in 1986. The reservoir is situated in a narrow Alpine valley, and significant sediment transport from upstream channel reaches resulted in a progressive reduction of the reservoir volume. From surveys of the sediment deposits in the hydropower lake, the annual sediment delivery has been estimated at 80000 to $100000 \mathrm{~m}^{3}$. The significant annual sediment deposits in relation to the total reservoir volume resulted in a threat of the safety of the infrastructures by potentially blocking the outlets. To solve this problem, a sediment bypass tunnel was constructed in 2012, with an intake structure on the right-hand side shore of the lake and an outlet structure downstream of the concrete dam. The purpose of the bypass tunnel is to purge coarse sediments regularly to the river channel downstream of the reservoir, during periods of elevated discharges resulting in significant sediment inputs into the reservoir. The sediment bypass tunnel has a length of $970 \mathrm{~m}$, a width of $4.4 \mathrm{~m}$ and a constant channel slope of $1.9 \%$ (Oertli and Auel, 2015). To monitor the bedload transport during the flushing operations, a Swiss plate geophone system (Rickenmann et al., 2014) was built at the outlet of the bypass channel (Fachini et al., 2015; Hagmann et al., 2015).

The Solis reservoir is fed by the two mountain rivers; the Albula and Julia. Two artificial lakes (hydropower reservoirs) in the Julia River limit the contribution of coarse sediment into the Solis reservoir. The main input of bedload particles to the Solis reservoir therefore stems from the Albula River. Another Swiss plate geophone system to monitor bedload transport in the Albula River was built in the village of Tiefencastel in spring 2015, some $1.5 \mathrm{~km}$ upstream of the upper end of the Solis hydropower reservoir. The main aims of the bedload transport monitoring at this site are: (i) to develop acoustic systems further for bedload transport measurements in coarse-bedded gravel bed rivers, and (ii) to determine a more reliable sediment budget in the area of the Solis reservoir and thus to help optimize sediment management during the flushing operations.

The new bedload measuring station is located at an elevation of $855 \mathrm{~m}$ a.s.l., where the catchment area is around $529 \mathrm{~km}^{2}$, of which only an insignificant portion is covered by glaciers $\left(<1 \mathrm{~km}^{2}\right)$. There are a number of water intakes related to the Solis hydropower plant, making the discharge and bedload transport partly dependent on hydroelectric operations. However, snowmelt during spring and early summer, together with rainfall events, represent the main periods of high discharges and bedload transport over the entire year.
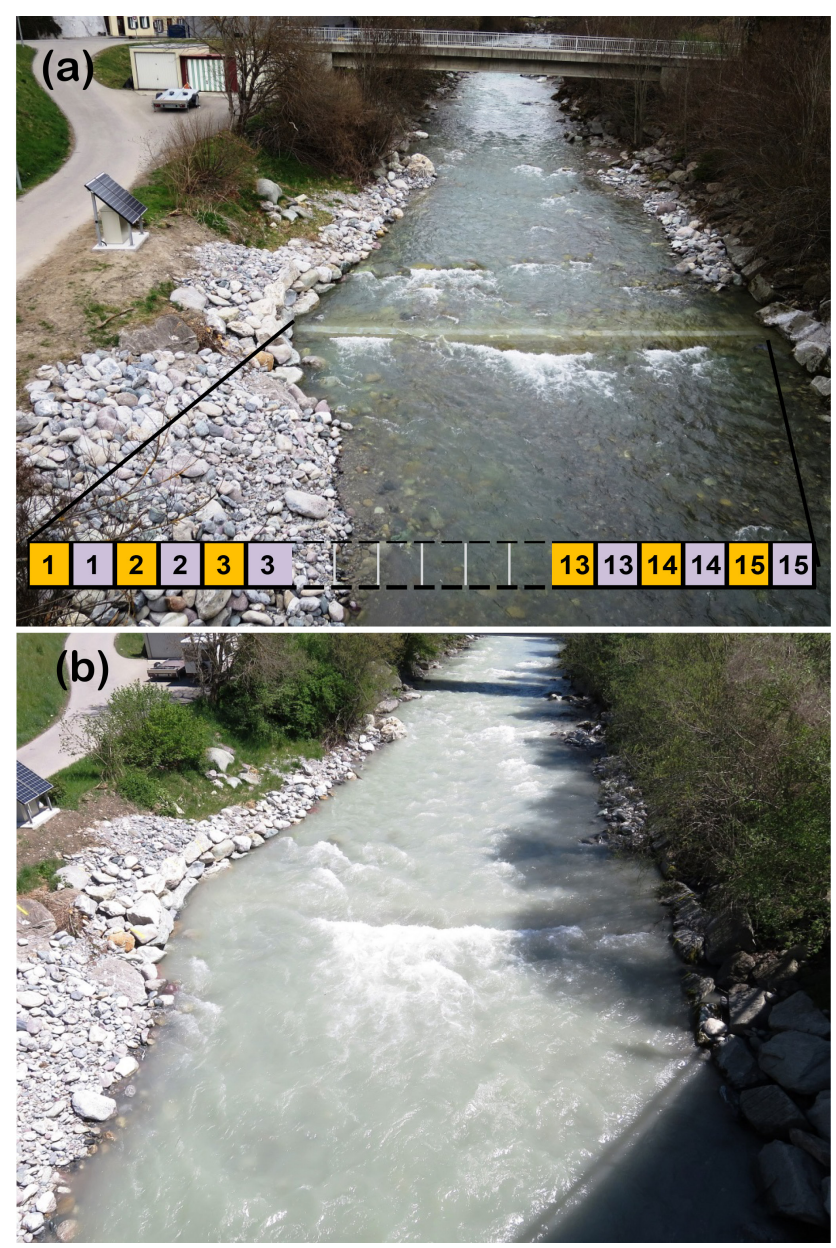

Figure 1. Bedload measuring site in the Albula River in Tiefencastel, Switzerland. Steel plates with acoustic sensors are embedded into a sill. The width of the sill is $15 \mathrm{~m}$, including a total of 30 steel plates with one sensor under each plate. Both geophones and accelerometers are installed. The view on the photos is upstream. (a) Low flow conditions on 16 April 2015 with a discharge of about $2 \mathrm{~m}^{3} \mathrm{~s}^{-1}$; numbers with yellow background refer to geophone sensors, numbers with violet background to accelerometer sensors (see also Table 1); (b) medium flow conditions on 7 May 2015 with a discharge of about $8 \mathrm{~m}^{3} \mathrm{~s}^{-1}$.

The channel width at the measuring cross-section in the Albula River at Tiefencastel is $15 \mathrm{~m}$. A concrete sill of the same width was installed, and a steel construction was embedded into the sill. A total of 30 steel plates were mounted flush with the sill level in the steel construction (Fig. 1). The downstream side of the sill is locally slightly steeper than the bed slope upstream of the sill, which should avoid sediment deposition over the steel plates. Each steel plate is acoustically separated by elastomer elements. The steel plates are $492 \mathrm{~mm}$ wide, $358 \mathrm{~mm}$ long (in the direction of flow), and $15 \mathrm{~mm}$ thick.

The 20DX geophone sensors from Geospace Technologies (Houston, Texas, USA) were installed in a PC801 LPC Land- 
case and fixed in an aluminium box under the steel plate. Moving bedload particles impacting the steel plate cause vibrations which are transmitted by the plate to the geophone sensor. The current induced is proportional to the vibration velocity of the sensor (Rickenmann and al., 2012). The accelerometer sensor is the model KS 78.10 from Metra Messund Frequenztechnik (Radebeul, Germany) with a sensitivity of $10 \mathrm{mV} \mathrm{g}^{-1}$, a maximum detectable acceleration of $\pm 500 \mathrm{~g}$ and a detectable frequency range of 0.56 to $23 \mathrm{kHz}$. The measuring system includes an industrial PC sampling the signal of the acoustic sensors with a frequency of $10 \mathrm{kHz}$ for both the geophone and accelerometer sensors (but including oversampling to prevent aliasing). To store the bedload transport measurements efficiently, summary values are calculated from the raw acoustic signal (Rickenmann et al., 2014) and these are stored with a resolution of one minute. Bedload transport intensity is expressed here by the number of impulses. Whenever the signal exceeds a preselected threshold value of $0.1 \mathrm{~V}$ (geophone sensors) or $0.4 \mathrm{~g}$ (accelerometer sensors), an impulse is recorded and the summed impulse counts (IMP) are stored for a given time interval of one minute.

For the first year of measurements (2015), only 23 sensors were connected to the data acquisition system (due to a limited number of available analogue-digital converter channels). During 2015, measurements were made with 15 Swiss plate geophones and 8 acceleration sensors distributed over the entire river cross-section, according to the scheme presented in Table 1.

To investigate the relationship between bedload transport and discharge at the Albula River, geophone and acceleration data were analysed together with discharge measurements. Discharge is measured at the stream gauging station of Tiefencastel, operated by the Federal Office of Environment (FOEN) and located some $500 \mathrm{~m}$ downstream of the acoustic bedload transport measuring station. These discharge data were corrected for bypassed water used by the hydropower company Albula-Landwasser Kraftwerke AG.

\section{Preliminary results and discussion}

\subsection{Comparison of measurements using the two sensor types}

In this section we consider data from the first "summer" season of measurements at the Albula station in Tiefencastel. For the period from 16 April until 5 July 2015, Fig. 2 presents discharge data together with the impulses summed over the 15 geophone sensors $\left(\mathrm{IMP}_{\mathrm{G}}\right)$. Discharge data show an increase in melt intensity from the beginning of May and discharge remains relatively high until the middle of July. Later, during the summer and autumn of 2015, discharge was mostly lower than $5 \mathrm{~m}^{3} \mathrm{~s}^{-1}$, and almost no geophone impulses were recorded. The geophone impulses correlate fairly well with discharge, and a critical discharge value cor-
Table 1. Numbering of the steel plates (left column) and the sensors (right column), indicting their lateral distribution; plate 1 is at river right hand side, plate 30 at river left hand side (see Fig. 1). Accelerometers in parenthesis were not connected to the data acquisition system during the measurements undertaken in 2015.

\begin{tabular}{ll}
\hline Plate & Sensor \\
\hline 1 & Geophone 1 \\
2 & Accelerometer 1 \\
3 & Geophone 2 \\
4 & (Accelerometer 2) \\
5 & Geophone 3 \\
6 & Accelerometer 3 \\
7 & Geophone 4 \\
8 & (Accelerometer 4) \\
9 & Geophone 5 \\
10 & Accelerometer 5 \\
11 & Geophone 6 \\
12 & (Accelerometer 6) \\
13 & Geophone 7 \\
14 & Accelerometer 7 \\
15 & Geophone 8 \\
16 & (Accelerometer 8) \\
17 & Geophone 9 \\
18 & Accelerometer 9 \\
19 & Geophone 10 \\
20 & (Accelerometer 10) \\
21 & Geophone 11 \\
22 & Accelerometer 11 \\
23 & Geophone 12 \\
24 & (Accelerometer 12) \\
25 & Geophone 13 \\
26 & Accelerometer 13 \\
27 & Geophone 14 \\
28 & (Accelerometer 14) \\
29 & Geophone 15 \\
30 & Accelerometer 15 \\
\hline &
\end{tabular}

responding to the start of bedload transport of about $5 \mathrm{~m}^{3} \mathrm{~s}^{-1}$ can be inferred from the geophone measurements.

Figure 3 compares discharge and number of impulses recorded by 8 acceleration sensors $\left(\mathrm{IMP}_{\mathrm{A}}\right)$. Generally, the trend is similar as for the geophone impulses, and again, the signal correlates fairly well with discharge. Nevertheless, some absolute and relative discrepancies can be noted. The acceleration sensors are more sensitive for recording higher frequency oscillations than the geophone sensors. In addition, the preselected threshold value for the impulse counts was found be relatively lower for the accelerometer signal $(0.4 \mathrm{~g})$ than for the geophone signal $(0.1 \mathrm{~V})$. For these reasons, the total number of impulses recorded by the accelerometers $\left(\mathrm{IMP}_{\mathrm{A}}\right)$ is around 31 times higher than the total number of impulses recorded by geophone $\left(\mathrm{IMP}_{\mathrm{G}}\right)$, if the impulse counts of the accelerometers are extrapolated to the same number of sensors as for the geophones. Furthermore, the accelerometer sensors also recorded (a relatively small 


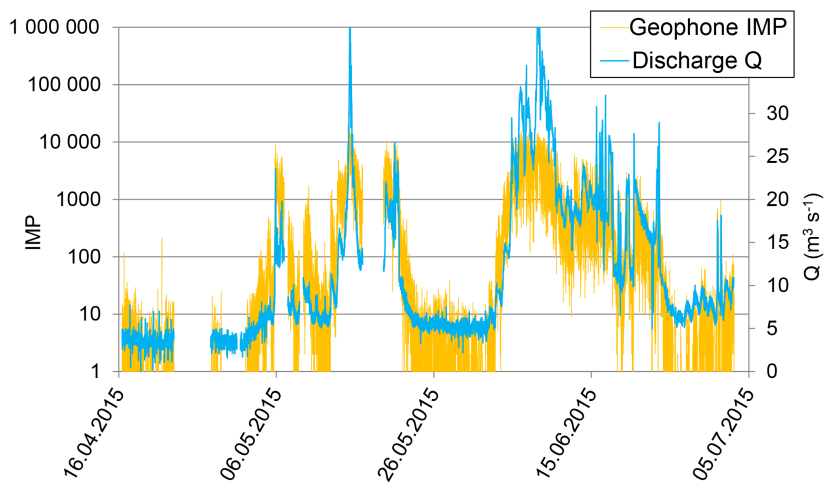

Figure 2. Discharge $(Q)$ and number of geophone impulses $\left(\mathrm{IMP}_{\mathrm{G}}\right)$ summed over the 15 geophone sensors, shown as a time series for the period 16 April until 5 July 2015.

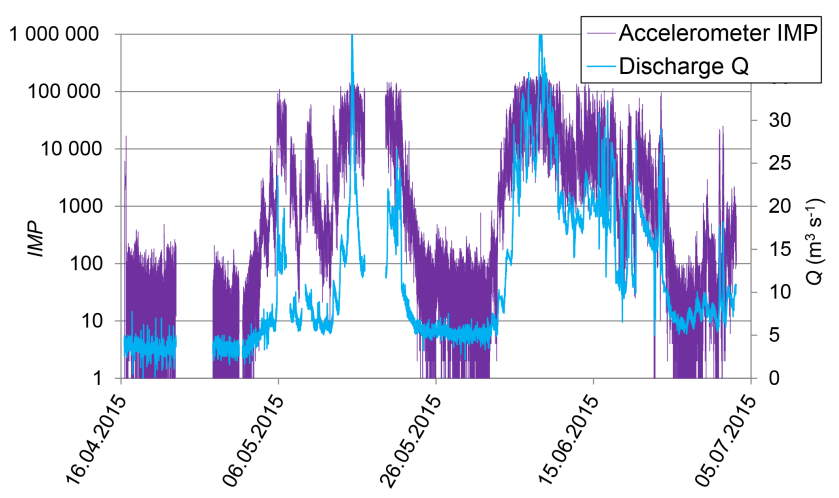

Figure 3. Discharge $(Q)$ and number of accelerometer impulses $\left(\mathrm{IMP}_{\mathrm{A}}\right)$ summed over 8 acceleration sensors, shown as a time series for the period 16 April until 5 July 2015.

number) of impulses later in the season, from July until October 2015, when discharge was mostly lower than $5 \mathrm{~m}^{3} \mathrm{~s}^{-1}$.

The sensor distribution over the cross-section allows investigation of the spatial distribution of bedload transport activity and impulse counts. Figure 4 shows the sum of impulses recorded with the two types of sensors summed over the entire season. To make the impulse counts comparable for the two sensor types, the number of impulses recorded by acceleration sensors was scaled using the following factor:

$\alpha=(8 / 15) \times\left(\Sigma \mathrm{IMP}_{\mathrm{G}} / \Sigma \mathrm{IMP}_{\mathrm{A}}\right)$

where $\Sigma \mathrm{IMP}_{\mathrm{A}}$ is the total number of impulses recorded by accelerometer sensors, $\Sigma \mathrm{IMP}_{\mathrm{G}}$ the total number of impulses recorded by geophone sensors over the entire season, and $(8 / 15)$ the ratio between the number of recording acceleration (8) and geophone (15) sensors, respectively.

After scaling, the number of impulses recorded by the acceleration sensors appears to follow a similar pattern regarding lateral bedload transport activity as recorded by the geophone sensors. The sensors that recorded the most impulses over the season are located in the middle of the stream (sen-

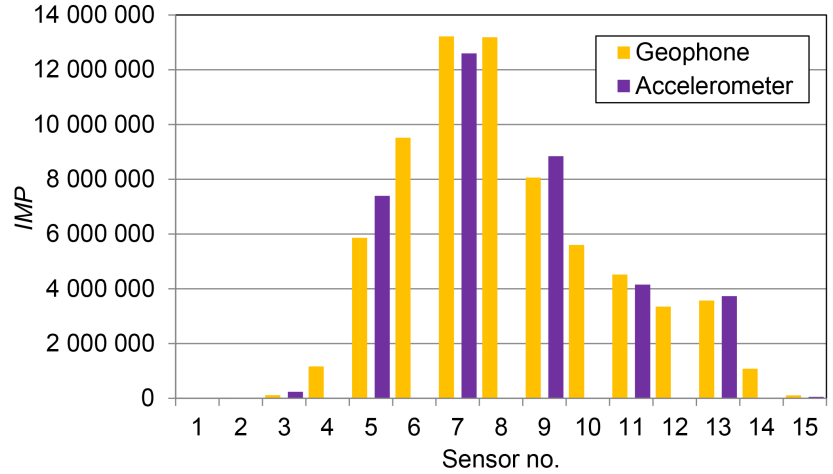

Figure 4. Total sum of impulses (IMP) recorded by each geophone sensor (yellow) and acceleration sensor (violet) during the summer of 2015. The number of impulses recorded by acceleration sensors was scaled according to Eq. (1). The view is in the upstream direction.

sors 7 and 8, corresponding to plate no. 13 to plate no. 15). From this location, the number of impulses recorded decreased gradually in both directions towards the river banks. However, the decline is more pronounced towards the orographic right bank (sensors 6 to 1 , plates no. 11 to no. 1), than towards the orographic left bank (sensors 9 to 15, plates no. 17 to no. 30 ).

It appears that both the geophone and the accelerometer sensors are suitable for indirect measurements of bedload transport in gravel-bed streams. The pre-processing using simple counts of impulses (i.e. excursions of the signal above a threshold amplitude value) also works for the accelerometer sensors. The bedload transport intensity, as expressed by the impulse counts, shows a reasonable dependence on discharge.

\subsection{Preliminary calibration of the Swiss plate geophone measuring system}

From previous investigations with the Swiss plate geophone (SPG) system, it is known that a liner relation between the number of impulses $\mathrm{IMP}_{\mathrm{G}}$ and mass $M$ of bedload transported over the steel plates provides a reasonable calibration relationship (Rickenmann et al., 2014):

$\mathrm{IMP}_{\mathrm{G}}=k_{b} M[\mathrm{~kg}]$

where $k_{b}\left[\mathrm{~kg}^{-1}\right]$ presents a linear calibration coefficient, which was found to depend on site-specific conditions.

For the Albula River measuring station, the total number of $\mathrm{IMP}_{\mathrm{G}}$ recorded for the summer 2015 was about $7 \times 10^{7}$ impulses. Since only half of the bedload transport activity was monitored by the geophone sensors (as there is an accelerometer sensor under every second plate), the total number of impulses for the entire channel width is about $\mathrm{IMP}_{\mathrm{G}, \text { tot }} \approx 1.4 \times 10^{8}$. For an average year, the total volume of sediment transported into lake Solis is about $90000 \mathrm{~m}^{3}$, 
which is largely input from the Albula River (see Sect. 2). The geophone measuring site is situated about $1.2 \mathrm{~km}$ upstream of the upper end of the lake, and the mean channel slope in this reach is about $1.2 \%$. The mean channel slope over $50 \mathrm{~m}$ upstream of the monitoring site is about $1 \%$. We therefore assume that over longer time periods, the sediment transport at the measurement site is similar to the sediment input to the lake. It is known from other studies that bedload transport volumes integrated over a certain time period correlate approximately linearly with the effective runoff volume $V_{\text {re }}$ (Rickenmann, 1997, 2001; Lenzi et al., 2004), which is the integration of the discharge above the critical discharge at initiation of transport, here taken as $25 \mathrm{~m}^{3} \mathrm{~s}^{-1}$ for the FOEN stream gauging station Tiefencastel at the Albula River, based on the acoustic measurements. The hydrologic year 2015 in Switzerland was generally quite dry. A comparison of the $V_{\text {re }}$ values for the Albula River at Tiefencastel for the years 1987 to 2014 suggests that the $V_{\text {re }}$ value for the year 2015 was only about $46 \%$ of an average year. It is also known from earlier studies with the SPG system, that the impulse counts with geophone sensors only detect particles larger than about $20 \mathrm{~mm}$. It is estimated that only about $20 \%$ of the sediment deposited in (the upper part of) the lake comprise particles coarser than $20 \mathrm{~mm}$, which is labelled here as $\mathrm{BL}_{20}$, and it is assumed that the deposits have a porosity of about $30 \%$ and that the grains have a density of $2650 \mathrm{~kg} \mathrm{~m}^{-3}$. Thus, the total mass of bedload transported past the geophone measurement site is estimated as: $\mathrm{BL}_{20}=$ $0.46 \times 90000 \mathrm{~m}^{3} \times 0.2 \times 0.7 \times 2650 \mathrm{~kg} \mathrm{~m}^{-3}=1.5 \times 10^{7} \mathrm{~kg}$. With these estimates, a mean calibration coefficient for the Albula River geophone monitoring site is estimated as $k_{b} \approx$ $\mathrm{IMP}_{\mathrm{G}, \text { tot }} / \mathrm{BL}_{20} \approx 9\left[\mathrm{~kg}^{-1}\right]$. This value is in a similar range as values determined from field calibration measurements based on direct bedload samples (Rickenmann et al., 2014).

A similar calculation can be made to arrive at a rough calibration of the accelerometer measurements. The following calibration relation is assumed to hold:

$\mathrm{IMP}_{\mathrm{A}}=k_{\mathrm{A}} M[\mathrm{~kg}]$

where $k_{\mathrm{A}}\left[\mathrm{kg}^{-1}\right]$ is a linear calibration coefficient. The total number of accelerometer impulses over the entire season and extrapolated to the entire channel width is about $\mathrm{IMP}_{\mathrm{A} \text {,tot }} \approx 4.3 \times 10^{9}$. Thus, a mean calibration coefficient for the Albula River accelerometer measurement system is estimated as $k_{\mathrm{A}} \approx \mathrm{IMP}_{\mathrm{A}, \text { tot }} / \mathrm{BL}_{20} \approx 290\left[\mathrm{~kg}^{-1}\right]$.

\section{Conclusions}

An impact measuring system using geophone and accelerometer sensors was successfully installed at the Albula River (Grisons, Switzerland), an alpine mountain river with a high annual rate of sediment transport (around $90000 \mathrm{~m}^{3} \mathrm{yr}^{-1}$ ). Preliminary results after one season of measurements showed a fairly good correlation between dis- charge and impulses recorded by both types of sensors, allowing the estimatation of a critical discharge corresponding to the start of bedload transport at around $5 \mathrm{~m}^{3} \mathrm{~s}^{-1}$ at the monitoring site. Most of the bedload activity occurred during the snow melt period, that is from the beginning of May until mid-July. Later, during the summer, and only for a few periods, weak bedload transport activity was recorded. Impact measuring systems also allow the investigation of the spatial distribution of bedload transport over the river crosssection. Sensors recorded a higher concentration of bedload in the middle of the stream with a gradual decrease towards the channel banks. A mean calibration coefficient for the geophone measurements was estimated based on the total number of impulses and the annual sediment delivery to the Solis lake. The calibration coefficient was found to be in a similar range to values determined previously from other sites with field calibration measurements.

\section{Data availability}

The data used in this study represent measurements of the first summer of recordings, and some values have to be used with caution (e.g. accelerometer impulses may include some signal noise due to the low threshold value). Those interested in using this data may contact the first author.

Competing interests. The authors declare that they have no conflict of interest.

Acknowledgements. The measuring installations and the study were supported by the Swiss Federal Office for the Environment through project "Geschiebemessungen mittels Geophonsensoren" (contract no. 06.0074.pz/m505-1377) and the Swiss Federal Research Institute WSL.

\section{References}

Badoux, A., Andres, N., and Turowski, J. M.: Damage costs due to bedload transport processes in Switzerland, Nat. Hazards Earth Syst. Sci., 14, 279-294, doi:10.5194/nhess-14-279-2014, 2014.

Beylich, A. A. and Laute, K.: Combining impact sensor field and laboratory flume measurements with other techniques for studying fluvial bedload transport in steep mountain streams, Geomorphology, 218, 72-87, 2014.

Fachini, M., Siviglia, A., and Boes, R. M.: Downstream morphological impact of a sediment bypass tunnel - preliminary results and forthcoming actions, in: Proc. First International Workshop on Sediment Bypass Tunnels, VAW-Mitteilungen 232, Laboratory of Hydraulics, Hydrology and Glaciology (VAW), ETH Zurich, Switzerland, 137-146, 2015.

Gray, J. R., Laronne, J. B., and Marr, J. D. G.: Bedload-surrogate Monitoring Technologies, U.S. Geological Survey Scientific Investigations Report 2010-5091, 37 pp., available at: http://pubs. usgs.gov/sir/2010/5091/, 2010. 
Hagmann, M., Albayrak, I., and Boes, R. M.: Field research: Invert material resistance and sediment transport measurements, in: Proc. First International Workshop on Sediment Bypass Tunnels, VAW-Mitteilungen 232, Laboratory of Hydraulics, Hydrology and Glaciology (VAW), ETH Zurich, Switzerland, 123-135, 2015.

Krein, A., Klinck, H., Eiden, M., Symader, W., Bierl, R., Hoffmann, L., and Pfister, L.: Investigating the transport dynamics and the properties of bedload material with a hydro-acoustic measuring system, Earth Surf. Proc. Land., 33, 152-163, 2008.

Lenzi, M. A., Mao, L., and Comiti, F.: Magnitude-frequency analysis of bed load data in an Alpine boulder bed stream, Water Resour. Res., 40, W07201, doi:10.1029/2003WR002961, 2004.

Mizuyama, T., Oda, A., Laronne, J. B., Nonaka, M., and Matsuoka, M.: Laboratory tests of a Japanese pipe geophone for continuous acoustic monitoring of coarse bedload, in: U.S. Geological Survey Scientific Investigations Report 2010-5091, 319-335, available at: https://pubs.usgs.gov/sir/2010/5091/papers/listofpapers. html, 2010a.

Mizuyama, T., Laronne, J. B., Nonaka, M., Sawada, T., Satofuka, Y., Matsuoka, M., Yamashita, S., Sako, Y., Tamaki, S., Watari, M., Yamaguchi, S., and Tsuruta, K.: Calibration of a passive acoustic bedload monitoring system in Japanese mountain rivers, in: U.S. Geological Survey Scientific Investigations Report 2010-5091, 296-318, available at: https://pubs.usgs.gov/sir/ 2010/5091/papers/listofpapers.html, 2010b.

Oertli, C. and Auel, C.: Solis sediment bypass tunnel: First operation experiences, in: Proc. First International Workshop on Sediment Bypass Tunnels, VAW-Mitteilungen 232, Laboratory of Hydraulics, Hydrology and Glaciology (VAW), ETH Zurich, Switzerland, 223-233, 2015.

Raven, E. K., Lane, S. N., and Ferguson, R.: Using sediment impact sensors to improve the morphological sediment budget approach for estimating bedload transport rates, Geomorphology, 119, 125-134, 2010.

Reid, S. C., Lane, S. N., and Berney, J. M.: The timing and magnitude of coarse sediment transport events within an upland gravelbed river, Geomorphology, 83, 152-182, 2007.

Rickenmann, D.: Sediment transport in Swiss torrents, Earth Surf. Proc. Land., 22, 937-951, 1997.

Rickenmann, D.: Comparison of bed load transport in torrents and gravel bed streams, Water Resour. Res., 37, 3295-3305, 2001.
Rickenmann, D.: Bedload transport measurements with geophones, hydrophones and underwater microphones (passive acoustic methods), in: Gravel Bed Rivers and Disasters, Wiley \& Sons, Chichester, UK, 185-208, in press, 2017a.

Rickenmann, D.: Bedload transport measurements with geophones and other passive acoustic methods, J. Hydraul. Eng.-ASCE, in press, 2017b.

Rickenmann, D., Turowski, J. M., Fritschi, B., Klaiber, A., and Ludwig, A.: Bedload transport measurements at the Erlenbach stream with geophones and automated basket samplers, Earth Surf. Proc. Land., 37, 1000-1011, 2012.

Rickenmann, D., Laronne, J. B., Turowski, J. M., and Vericat, D. (Eds.): International Workshop of Acoustic and Seismic Monitoring of Bedload and Mass Movements, Abstracts, Birmensdorf, Switzerland, Swiss Federal Research Institute WSL, 109 pp., 2013.

Rickenmann, D., Turowski, J. M., Fritschi, B., Wyss, C., Laronne, J. B., Barzilai, R., Reid, I., Kreisler, A., Aigner, J., Seitz, H., and Habersack, H.: Bedload transport measurements with impact plate geophones: comparison of sensor calibration in different gravel-bed streams, Earth Surf. Proc. Land., 39, 928-942, 2014.

Tsakiris, A. G., Papanicolaou, A. N., and Lauth, T. J.: Signature of bedload particle transport mode in the acoustic signal of a geophone, J. Hydraul. Res., 52, 185-204, 2014.

Wyss, C. R., Rickenmann, D., Fritschi, B., Turowski, J. M., Weitbrecht, V., and Boes, R. M.: Measuring bedload transport rates by grain-size fraction using the Swiss plate geophone signal at the Erlenbach, J. Hydraul. Eng.-ASCE, 142, 04016003, doi:10.1061/(ASCE)HY.1943-7900.0001090, 2016a.

Wyss, C. R., Rickenmann, D., Fritschi, B., Turowski, J. M., Weitbrecht, V., and Boes, R. M.: Laboratory flume experiments with the Swiss plate geophone bedload monitoring system. Part I: Impulse counts and particle size identification, Water Resour. Res., 52, 7744-7759, doi:10.1002/2015WR018555, 2016 b.

Wyss, C. R., Rickenmann, D., Fritschi, B., Turowski, J. M., Weitbrecht, V., Travaglini, E., Bardou, E., and Boes, R. M.: Laboratory flume experiments with the Swiss plate geophone bedload monitoring system. Part II: Application to field sites with direct bedload samples, Water Resour. Res., 52, 7760-7778, doi:10.1002/2016WR019283, 2016c. 